\title{
Research Paper: Effects of Custom-mold Insole by Medial Heel Skive Technique on Physical Function in Flexible Flat Foot
}

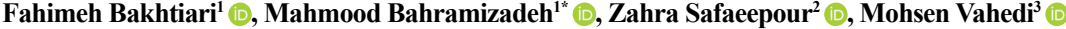

1. Department of Orthotics \& Prosthetics, University of Social Welfare and Rehabilitation Sciences, Tehran, Iran.

2. Department of Human Performance and Health, University of South Carolina Upstate, Spartanburg, South Carolina, USA

3. Department of Biostatistics and Epidemiology, University of Social Welfare and Rehabilitation Sciences, Tehran, Iran.

\begin{tabular}{|c|c|}
\hline $\begin{array}{l}\text { Use your device to scan } \\
\text { and read the article online }\end{array}$ & Citation: Bakhtiari F, Bahramizadeh M, Safaeepour Z, Vahedi M. Effects of Custom-mold Insole by Medial Heel Skive \\
\hline 口ifiris & $\begin{array}{l}\text { Technique on Physical Function in Flexible Flat Foot. Iranian Rehabilitation Journal. 2021; 19(2):181-188. http://dx.doi. } \\
\text { org/10.32598/irj.19.2.1383.1 }\end{array}$ \\
\hline 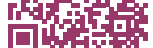 & 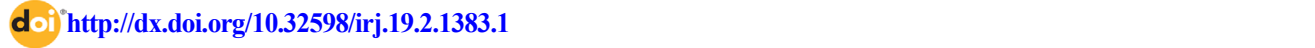 \\
\hline
\end{tabular}

Article info:

Received: 26 Mar 2021

Accepted: 17 May 2021

Available Online: 01 June 2021

\section{Keywords:}

Foot orthosis, Orthotic insole, Flat foot, Flexible flat foot, Physical function, Insole

\section{ABSTRACT}

Objectives: Flexible Flat Foot (FFF), a common foot deformity decreasing medial longitudinal arch height is often comorbid with subtalar joint pronation causing physical activity difficulties in this population. Among the orthotic insoles prescribed for improving foot function, foot orthoses with medial heel skive technique have a limited research background. The present study aimed to investigate the effects of the custom-mold insole with medial heel skive technique on physical function in FFF.

Methods: Eighteen adults with FFF from the University of Social Welfare and Rehabilitation Sciences students and staff participated in this study. Custom-Mold insole with medial heel skive was fabricated for all research participants. Physical function in the activities of daily living and sports was assessed by the Foot and Ankle Ability Measure (FAAM), Activities of Daily Living (ADL) subscale (ADL-FAAM), and SPORT-FAAM questionnaires at the beginning of the study and 6 weeks after. Paired Samples t-test and nonparametric tests were used to compare the collected results.

Results: After 6 weeks of using the insole with medial heel skive technique, scores in both ADL and SPORTS activities were significantly improved.

Discussion: Foot function improvement was not found in all of the studies assessing foot function in flat feet after using different orthotic insoles, by different questionnaires or other systems. In this study, foot and ankle function was significantly improved per FAAM questionnairewhich had highly limited use in orthotic interventions in flat feet population- using medial heel skive technique; however, further studies are required to accentuate medial heel skive technique effect on flat feet function by comparing this technique with other positive cast modifications to control the flat foot. According to the present study results, custom-mold insole with medial heel skive may improve physical function in FFF and can be prescribed in this group. 


\section{Highlights}

- Custom-mold insole with medial heel skive may significantly improve foot and ankle function in flexible flat feet.

- Activities of daily living such as standing, walking and squatting and higher difficult activities such as doing sports, running or jumping may improve by this technique.

- The total definition of foot function level by flat feet individuals may improve and be described more "normal".

\section{Plain Language Summary}

Flat feet is a musculoeskeletal disorder and the lack of the arch in the midpart of your foot can cause you difficulty in physical activities such as standing, walking or running and so on. insoles can prevent function difficulties by supporting your midfoot arch. In this research the technique of rotating the heel was studied and the results after using this insoles in flat feet adults shoes can improve their physical function; thus, it may be prescribed.

\section{Introduction}

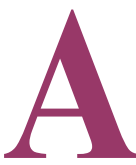

ny foot structures supporting medial longitudinal arch improper function can cause flat foot, decreasing of the arch height [1]. Optimal lower limb function requires healthy foot function, decreasing the risk of injuries during the physical Activities of Daily Living (ADL), practicing sports, and running. Foot pronation with talus plantar flexion and calcaneus lateral rotation is an essential part of the flat feet biomechanical malalignment most of the time; thus condition changes normal foot and lower limb efficient function during movement [2, 3]. Flat feet are highly prevalent among individuals globally; with $37.95 \%$ and $55.55 \%$ prevalence rates among females and males $[4,5]$. Medial longitudinal arch height may become normal following growing up and skeletal maturity $[6,7]$; however, there is a $26.62 \%$ adult flat feet reported [8]. A flat foot causes difficulties in physical functions, such as difficulty during long time standing [9]; more energy consumption during walking due to the loss of midfoot rocker; greater fatigue during physical activities induced by increased muscle activity compensating the loss of arch $[10,11]$. Overuse syndromes, like patellofemoral pain during running and practicing sports are another result of a malalignment of foot structures [3]. Dynamic balance may affect lower limb functions, such as stepping up and down curbs or walking on uneven ground. It also is disordered in flat feet due to excessive tension in foot tissues and their receptors [12].

Orthotic insoles supporting medial longitudinal arch are a conservative treatment for flat feet; thus, they are more preferred to foot surgeries without desirable or permanent results [12-17]. Taspinar suggested that arch support is effective in improving foot function [18]. Arastoo improved the jumping function in footballers with orthotic insoles [19]. However, some studies found no changes in function after using orthotic insoles. For example, Banwel and Yurt assessed flat feet function after using orthotic insoles for a while [20, 21]. Walking uphill was also harder for flat feet individuals using arch supports in Huang's study [22]. Kirby claimed that the medial heel skive technique is useful to control pronated feet [23]. Bahramian studied the effect of medial heel skive technique on flat feet function; however, they only assessed women's feet in a pilot study, i.e., documented in Persian [24]. The current study aimed to assess both genders with flat feet using a different measuring tool intervening foot orthoses with medial heel skive technique. There is a high prevalence of flat feet; however, adults' flatfeet remain an issue disordering physical function. Besides, limited studies explored medial heel skive technique in controlling flat feet; thus, it seemed necessary to perform this research.

\section{Methods}

Eighteen active adults, including 8 males and $10 \mathrm{fe}$ males with flexible flat feet participated in this study. The study subjects were chosen by convenience sampling method from the students and staff of the University of Social Welfare and Rehabilitation Sciences. The study process was completely explained to all research participants. They voluntarily participated in this study and were allowed to discontinue co-operation whenever desired. The inclusion criteria of the study were as fol- 
lows: the age range of $18-60$ years [25]; +6 foot posture index or more [24], and having flexible and mobile flat feet according to the tiptoe test data [26]. The ones having rigid flat feet, a history of trauma, fracture, or surgery in the lower limb, neurological disorders, such as Cerebral Palsy (CP), Polio, spina bifida [24], or any neurological conditions in the foot and lower limb length discrepancy [27] were excluded from this study. This study was approved by the Ethics Committee of the University of Social Welfare and Rehabilitation Sciences (Code: IR.USWR.REC.1399.135).

Negative casting was performed for manufacturing custom-mold foot orthoses for all study participants in the none weight-bearing and neutral position of the subtalar joint [24]. In addition to medial longitudinal arch support, the medial heel skive technique was applied to the positive cast. This attempt was achieved by making an even surface ellipse with a $4-\mathrm{mm}$ depth having a $15^{\circ}$ angle with forefoot medially. The edges of the ellipse were rounded to keep the circled shape of the heel and not to irritate individuals> feet [23]. The main insole was made from $3-5 \mathrm{~mm}$ (according to individuals weight) polypropylene thermoplastic sheet manually molded on the positive cast after warming up. Foot orthosis had an infra malleolar trim line and $\geq 18 \mathrm{~mm}$ height of the heel cup to properly control the subtalar joint. Polypropylene shell was anteriorly extended just proximal to the metatarsal heads $[23,28,29]$. The final free orthotic insole had a Varus wedge inside the heel cup. This measure aimed to control subtalar pronation as well as medial longitudinal arch support (Figure 1). The study participants were requested to put the insole in their laced sports shoes and use the insole 6-8 hours per day to be effective [30]. The following mearing tools were employed in this research:

Foot posture index with 6 items: Talus head palpation, supra, and infra lateral malleolar curvature, the inversion/eversion of the calcaneus, bulging in the talonavicular joint, the congruence of the medial longitudinal arch, and the abduction/adduction of the forefoot was used to assess foot pronation. Moreover, -2 to +2 points can be dedicated to each item; thus, the total score ranges from -12 to +12.0 score, indicating normal foot; tending to scores reflects supinated foot, and + scores represent pronated foot [31]. Individuals obtaining +6 or more positive foot scores were considered as flat feet and entered this study [24]. The mobility of the flat foot was checked by tiptoe test when having arch height back by standing on toes [13].

For assessing physical function in the examined flat feet participants, the Foot and Ankle Ability Measure (FAAM) was used. Self-Reported FAAM questionnaire contains 2 parts; Activities of Daily Living (ADL) and SPORT with foot and ankle functions having 5-option assessing the difficulty of each function. The study participants should describe the difficulty of functions from no difficulty condition to unable to do. Furthermore, 21 items belong to ADL, such as standing, walking, using stairs, and squatting. Besides, there are 8 items for sports activities that require higher levels of physical activity, such as running, jumping, and landing. Each item is dedicated 0 to 4 scores with higher scores reflecting greater foot and ankle ability, i.e., reported in percentage. The study participants are also given a total percentage, ranging from 0 to 100 to their current level of function at the end of each part. They also define their overall level of function at the end of the questionnaire in 4 conditions, as follows: normal, nearly normal, abnormal, or severely abnormal. The validity and reliability of the FAAM were supported in previous studies [32]. The research participants' foot and ankle function was assessed at the beginning of the study when no foot orthosis was used and at the end of the study (after 6 weeks of using orthotic insole) [24].

The software SPSS v. 22 was used for data analysis. The normal distribution of the collected data was checked by the Shapiro-Wilk test. The comparison between pretests and posttests data was performed by Paired Samples ttest for normally distributed; nonparametric Wilcoxon test was applied for analyzing the data without normal distribution.

\section{Results}

In total, $18(8$ males \& 10 females) flexible flat feet adults with an foot function index (FPI) of more than +6 ; a Mean \pm SD age of $33.11 \pm 13.42$ years, weight: $70.8 \pm 16.59 \mathrm{~kg}$, and height: $168 \pm 9.73 \mathrm{~cm}$ participated in this study (Table 1). The Mean/Mode \pm SD of the physical function variables in pretests and posttests, with the test of normality of data distribution are listed in Table 2. This study investigated whether the custom-mold orthotic insole with medial heel skive technique improves physical function in adult flexible flat feet individuals after 6 weeks or not.

According to Table 3, the ADL score and the total percentage were significantly increased in the study participants $(\mathrm{P}<0.01)$. A significant increase was also detected in the sport part of the functions, both in scores $(\mathrm{P}<0.05)$ and percentage $(\mathrm{P}<0.01)$. The description of foot and ankle function level (from severely abnormal to normal) was improved as well $(\mathrm{P}<0.01)$ (Table 4$)$. The pretest and posttest data were compared by the nonpara- 


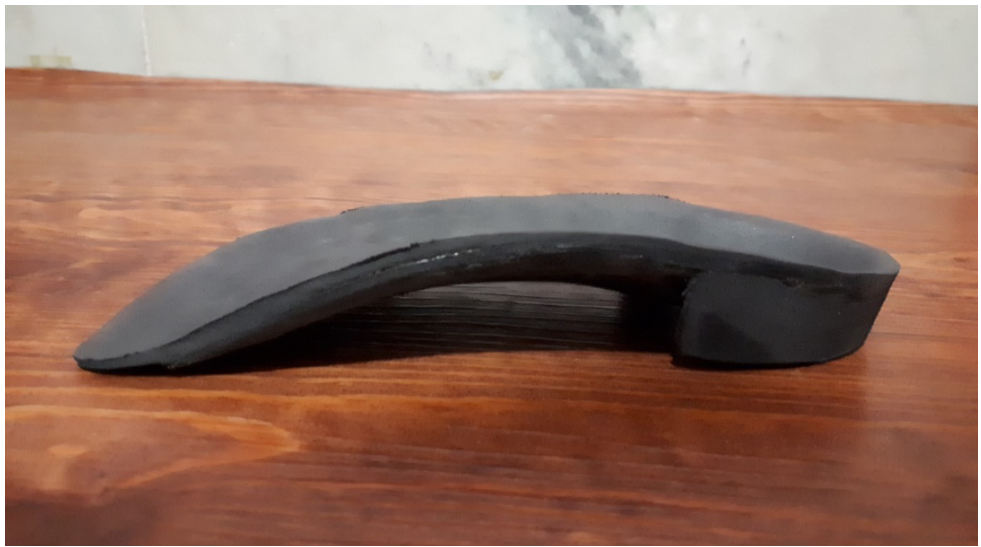

Figure 1. The orthotic insole used in this study

Iranian Rehabilitation Journal

metric Wilcoxon test. This was because of the abnormal distribution of the data in variables; however, the sport function scores presented a normal distribution and were compared by Paired Samples t-test. The P-value for the t-test was below 0.05; for the Wilcoxon test, this value was below 0.01, suggesting a significant difference between the pretest and posttest data, which compares function level descriptions before and after using foot orthosis (Table 4). As a result, there was a foot and ankle function improvement in the study subjects.

\section{Discussion}

The present study aimed to investigate physical function in flat foot individuals after using orthotic insoles with medial heel skive technique for 6 weeks. According to the obtained results, foot and ankle function scores in ADL significantly increased from 83.73 to 98.25 ; the percentage given to these functions significantly increased from $76.11 \%$ to $96.5 \%$ as well. The SPORT functions (activities with a higher level of difficulty) score significantly increased from 77.63 to 95.11 . The total percentage given to these functions by individuals also significantly increased from $70 \%$ to $92.06 \%$. The description of foot and ankle function levels was also significantly improved. According to Table 4, initially, $22.22 \%$ of the research participants reported their foot function normal, and the rest $55.56 \%$ and $22.22 \%$ reported their function level nearly normal and abnormal, respectively. After 6 weeks of using the orthotic insole, there was a 5.56\% report for nearly normal and $94.44 \%$ of the study participants reported their foot function as normal (Table 4). Thus, we can suggest that physical function may be approved by this technique.

The current study results found were limited to this study and its method. Among the techniques introduced to control subtalar pronation, such as Blake's inversion technique [33], root model [34], and University of California Berkeley Laboratories (UCBL) orthosis [35], the medial heel skive was introduced by Kirby [23]. UCBL foot orthosis keeps subtalar joint in neutral position having high medial and lateral extended trim line [35]. The Root model also was introduced intending to keep the heel in a vertical position by making a vertical heel in the positive cast [35]. Blake's technique puts the heel cup in a varus position by angling it medially; however, sometimes, the rounded shape of the heel in individuals and heel sliding prevents the subtalar joint from remaining in a Varus position [33]. For further controlling pronation, medial wedges are also added under the heel or along with the insole [29].

Table 1. Demographic information of the study participants

\begin{tabular}{cccc}
\hline Variables & Mean \pm SD & Min & Max \\
\hline Age, $y$ & $33.11 \pm 13.42$ & 18 & 57 \\
Weight, $\mathrm{kg}$ & $70.98 \pm 16.59$ & 43 & 100 \\
Height, $\mathrm{cm}$ & $168 \pm 9.73$ & 153 & 182 \\
FPI & $8.28 \pm 1.45$ & $7+$ & $12+$ \\
\hline
\end{tabular}


Table 2. Descriptive statistics and the test of normality of the physical function variables

\begin{tabular}{|c|c|c|c|c|c|c|}
\hline \multirow{2}{*}{ Characteristic } & \multicolumn{3}{|c|}{ Pretest } & \multicolumn{3}{|c|}{ Posttest } \\
\hline & \multicolumn{2}{|c|}{ Mean/Mode $\pm S D$} & Shapiro-Wilk & \multicolumn{2}{|c|}{ Mean/Mode \pm SD } & Shapiro-Wilk \\
\hline ADL score & \multicolumn{2}{|c|}{$87.73 \pm 12.31$} & 0.002 & \multicolumn{2}{|c|}{$98.25 \pm 3.48$} & 0.0001 \\
\hline ADL \% & \multicolumn{2}{|c|}{$76.11 \pm 14.09$} & 0.082 & \multicolumn{2}{|c|}{$95.11 \pm 6.53$} & 0.001 \\
\hline SPORT score & \multicolumn{2}{|c|}{$77.63 \pm 16.44$} & 0.196 & \multicolumn{2}{|c|}{$96.5 \pm 5.93$} & 0.0001 \\
\hline SPORT \% & \multicolumn{2}{|c|}{$70 \pm 20.22$} & 0.709 & \multicolumn{2}{|c|}{$92.06 \pm 14.42$} & 0.0001 \\
\hline Function defining & 3 (nearly normal) & 0.69 & 0.002 & 4 (normal) & 0.24 & 0.0001 \\
\hline
\end{tabular}

According to the comparative studies, insoles with medial wedges are more effective in controlling pronation, compared to insoles with a heel in a neutral position [36]. Kirby claimed that along with decreased modification in the positive cast, medial heel skive presents a better effect in controlling foot pronation [23]. Orthotic insole with medial heel skive will have a Varus wedge just inside the heel cup. Moreover, medial heel skive displaces the vertical force applied from the heel cup to subtalar joint to correct foot pronation. By displacing the correcting force more medially, the supinator torque generated over the pronated subtalar joint becomes stronger due to lengthening of the orthosis force [23].
Comparing this technique to the previously introduced techniques may further support the effectiveness of adding medial heel skive to orthotic insoles; we can observe function improvement in studies using orthotic insoles without medial heel skives, such as those by Taspinar and Arastoo. However, flat feet function was assessed by different means in these studies [18, 19]. Arastoo measured forces during vertical jumping using a force plate [19]. FAAM with limited use in flat feet interventions was applied in this study. Taspinar and Bahramian studied function by FFI and FAOS questionnaires, respectively, which reported improved function $[18,24]$.

The materials used for manufacturing orthotic insole may also be effective on flat feet function. Huang used

Table 3. Comparing results of the function variables after 6 weeks using orthotic insole

\begin{tabular}{|c|c|c|c|c|c|c|}
\hline \multirow{3}{*}{$\begin{array}{l}\text { Variables } \\
\text { ADL score }\end{array}$} & \multicolumn{4}{|c|}{ Mean/Mode $\pm S D$} & \multirow{3}{*}{$\begin{array}{c}\text { Mean Difference } \\
14.52\end{array}$} & \multirow{3}{*}{$\begin{array}{c}\mathbf{P} \\
0.000\end{array}$} \\
\hline & \multicolumn{2}{|c|}{ Before } & \multicolumn{2}{|c|}{ After } & & \\
\hline & 83.73 & 12.31 & 98.25 & 3.48 & & \\
\hline ADL \% & 76.11 & 14.09 & 96.5 & 5.93 & 20.39 & 0.000 \\
\hline SPORT score & 77.63 & 16.44 & 95.11 & 6.53 & 17.48 & 0.000 \\
\hline SPORT \% & 70 & 20.22 & 92.06 & 14.42 & 22.06 & 0.001 \\
\hline Function description & $\begin{array}{c}3 \\
\text { (nearly normal) }\end{array}$ & 0.69 & $\begin{array}{c}4 \\
\text { (normal) }\end{array}$ & 0.24 & - & 0.001 \\
\hline
\end{tabular}

Iranian Rehabitation Dournal

Table 4. Describing foot and ankle function levels before and after using orthotic insole

\begin{tabular}{ccccc}
\hline Function Levels & Normal & Nearly Normal & Abnormal & Severely Abnormal \\
\hline Before & $22.22 \%$ & $55.56 \%$ & $22.22 \%$ & 0 \\
After & $94.44 \%$ & $5.56 \%$ & 0 & 0 \\
\hline
\end{tabular}

Iranian Rehabilitation Journa 
hard arch supports walking uphill with the orthotic insole, i.e., harder, compared to walking without insoles or downhill walking [22]. Hard thermoplastic insole significantly improved flat feet function in this study; however, the mean score failed to reach 100. Thus, investigating the effect of this technique by different insole materials may be necessary. Such an attempt may help to examine the material effects on improving function with the foot orthosis. Further studies with larger sample sizes are also suggested to make the results of this study extendable to the whole population.

\section{Conclusion}

According to this study, custom-mold orthotic insole with medial heel skive technique may significantly improve the ability of foot and ankle in physical functions, in ADL and SPORT after 6 weeks using orthotic insole. Thus, an orthotic insole with this technique may be recommended as an orthotic treatment option to improve the disordered physical function of the foot and ankle in a flexible flat foot.

\section{Ethical Considerations}

\section{Compliance with ethical guidelines}

This study was approved by the Ethics Committee of the University of Social Welfare and Rehabilitation Sciences (Code: IR.USWR.REC.1399.135).

Funding

This research did not receive any grant from funding agencies in the public, commercial, or non-profit sectors.

\section{Authors' contributions}

All authors equally contributed to preparing this article.

\section{Conflict of interest}

The authors declared no conflicts of interest

\section{Acknowledgments}

This research was conducted at the University of Social Welfare and Rehabilitation Sciences (USWR) while casting and instructing insoles. Consultative help from Dr. Safaeepour from the University of South Carolina Upstate was used for performing this study. The researcher appreciates all assistants, students, and staff in USWR who contributed to this study.

\section{References}

[1] Van Boerum DH, Sangeorzan BJ. Biomechanics and pathophysiology of flat foot. Foot and Ankle Clinics. 2003; 8(3):41930. [DOI:10.1016/S1083-7515(03)00084-6] [PMID]

[2] Levy JC, Mizel MS, Wilson LS, Fox W, McHale K, Taylor DC, et al. Incidence of foot and ankle injuries in West Point cadets with pes planus compared to the general cadet population. Foot \& Ankle International. 2006; 27(12):1060-4. [DOI:10.1177 /107110070602701211] [PMID]

[3] Subotnick SI. Orthotic foot control and the overuse syndrome. The Physician and Sportsmedicine. 1975; 3(1):75-9. [DOI:10.1080/00913847.1975.11948130] [PMID]

[4] Ibeabuchi M, Obun C, Olabiyi O, Oluwabusola E, Adebayo A. Prevalence of flat foot among 6-15 year old Nigerian school children resident in Lagos. Journal of Anatomical Sciences. 2020; 11(2):153-8. file:///C:/Users/b.fallahi/Downloads/ IbeabuchiM.pdf

[5] Patel C, Mehta P. Prevalence of flat foot and correlation between BMI and Planter Arch Index in obese school children Indian Journal of Physiotherapy \& Occupational Therapy. 2020; 14(3):182-6. [DOI:10.3928/01477447-20090101-26]

[6] Vittore D, Patella V, Petrera M, Caizzi G, Ranieri M, Putignano P, et al. Extensor deficiency: First cause of childhood flexible flat foot. Orthopedics. 2009; 32(1):28. [DOI:10.3928/0147744720090101-26] [PMID]

[7] Volpon JB. Footprint analysis during the growth period. Journal of Pediatric Orthopedics. 1994; 14(1):83-5 [DOI:10.1097/01241398-199401000-00017] [PMID]

[8] Pita-Fernandez S, Gonzalez-Martin C, Alonso-Tajes F, Seoane-Pillado T, Pertega-Diaz S, Perez-Garcia S, et al. Flat foo in a random population and its impact on quality of life and functionality. Journal of Clinical and Diagnostic Research 2017; 11(4):LC22-7. [DOI:10.1007/s00296-017-3817-z] [PMID]

[9] Kaufman KR, Brodine SK, Shaffer RA, Johnson CW, Cullison TR. The effect of foot structure and range of motion on musculoskeletal overuse injuries. The American Journal of Sports Medicine. 1999; 27(5):585-93. [DOI:10.1177/036354659 90270050701] [PMID]

[10] Murley GS, Landorf KB, Menz HB, Bird AR. Effect of foot posture, foot orthoses and footwear on lower limb muscle activity during walking and running: A systematic review. Gait \& Posture. 2009; 29(2):172-87. [DOI:10.1016/j.gaitpost.2008.08.015] [PMID]

[11] Otman S, Basgöze O, Gökce-Kutsal Y. Energy cost of walking with flat feet. Prosthetics and Orthotics International 1988; 12(2):73-6. [DOI:10.3109/03093648809078203] [PMID]

[12] Kodithuwakku Arachchige SNK, Chander H, Knight A. Flatfeet: Biomechanical implications, assessment and management Foot. 2019; 38:81-5. [DOI:10.3109/03093648809078203] [PMID]

[13] Atik A, Ozyurek S. Flexible flatfoot. Northern Clinics of Istanbul. 2014; 1(1):57-64. [DOI:10.14744/nci.2014.29292]

[14] Crego Jr Ch, Ford LT. An end-result study of various operative procedures for correcting flat feet in children. The Journal of Bone \& Joint Surgery. 1952; 34(1):183-95. [DOI:10.2106/00004623-195234010-00022] 
[15] Tsung BY, Zhang M, Mak AF, Wong MW. Effectiveness of insoles on plantar pressure redistribution. Journal of Rehabilitation Research and Development. 2004; 41(6A):767-74. [DOI:10.1682/JRRD.2003.09.0139] [PMID]

[16] Collins N, Bisset L, McPoil T, Vicenzino B. Foot orthoses in lower limb overuse conditions: A systematic review and meta-analysis. Foot \& Ankle International. 2007; 28(3):396-412. [DOI:10.3113/FAI.2007.0396] [PMID]

[17] Sheikh Taha AM, Feldman DS. Painful flexible flatfoot. Foot and Ankle Clinics. 2015; 20(4):693-704. [DOI:10.1016/j. fcl.2015.07.011] [PMID]

[18] Taspinar O, Kabayel DD, Ozdemir F, Tuna H, Keskin Y, Mercimek OB, et al. Comparing the efficacy of exercise, internal and external shoe modification in pes planus: A clinical and pedobarographic study. Journal Of Back And Musculoskeletal Rehabilitation. 2017; 30(2):255-63. [DOI:10.3233/ BMR-150399] [PMID]

[19] Arastoo AA, Aghdam EM, Habibi AH, Zahednejad S Kinetic factors of vertical jumping for heading a ball in flexible flatfooted amateur soccer players with and without insole adoption. Prosthetics and Orthotics International. 2014; 38(3):204-10. [DOI:10.1177/0309364613492790] [PMID]

[20] Banwell H, Mackintosh S. Changes in the six-minute walk test and foot health status using customised foot orthoses vs sham inserts in an adult flat foot population. A pilot randomised control trial. The Allied Health Scholar. 2020; 1(1):87-115. [DOI:10.21913/TAHS.v1i1.1565]

[21] Yurt Y, Şener G, Yakut Y. The effect of different foot orthoses on pain and health related quality of life in painful flexible flat foot: A randomized controlled trial. European Journal of Physical and Rehabilitation Medicine. 2019; 55(1):95-102. [DOI:10.23736/S1973-9087.18.05108-0] [PMID]

[22] Huang YP, Kim K, Song CY, Chen YH, Peng HT. How arch support insoles help persons with flatfoot on uphill and downhill walking. Journal of Healthcare Engineering. 2017; 2017:9342789. [DOI:10.1155/2017/9342789] [PMID]

[23] Kirby KA. The medial heel skive technique. Improving pronation control in foot orthosis. Journal of the American Podiatric Medical Association. 1992; 82(4):177-88. [DOI:10.7547/87507315-82-4-177] [PMID]

[24] Bahramian F, Abootorabi A, Zarezadeh F, Rezaeian T. [Effect of custom-molded insole with new technique on pain and function in females with flexible flat foot: A pilot study (Persian)]. Journal of Rehabilitation. 2017; 17(4):318-25. [DOI:10.21859/jrehab-1704318]

[25] Hutchison MK, Houck J. Can foot exercises and barefoot weight bearing improve foot function in participants with flat feet? Orthopedic Research Online Journal. 2018; 3(4):254-63. [DOI:10.21859/jrehab-1704318]

[26] Khodaei B, Saeedi H, Jalali M, Farzadi M, Norouzi E. Comparison of plantar pressure distribution in CAD-CAM and prefabricated foot orthoses in patients with flexible flatfeet. The Foot. 2017; 33:76-80. [DOI:10.1016/j.foot.2017.07.002] [PMID]

[27] Aminian G, Safaeepour Z, Farhoodi M, Pezeshk AF, Saeedi H, Majddoleslam B. The effect of prefabricated and proprioceptive foot orthoses on plantar pressure distribution in patients with flexible flatfoot during walking. Prosthetics and Orthotics International. 2013; 37(3):227-32. [DOI:10.1177/0309364612461167] [PMID]
[28] Bonanno DR, Zhang CY, Farrugia RC, Bull MG, Raspovic AM, Bird AR, et al. The effect of different depths of medial heel skive on plantar pressures. Journal of Foot and Ankle Research. 2012; 5:20. [DOI:10.1186/1757-1146-5-20] [PMID]

[29] Webster JB, Murphy DP. Atlas of orthoses and assistive devices. Amsterdam: Elsevier; 2017. https://www.google. co.uk/books/edition/Atlas_of_Orthoses_and_Assistive_De vices $/ 6$ RNBDwAAQBAJ?hl=en\&gbpv $=1 \& \mathrm{dq}=$ Atlas + of + Ort hoses+and+Assistive+Devices\&printsec $=$ frontcover

[30] Xu R, Wang Z, Ren Z, Ma T, Jia Z, Fang S, et al. Comparative study of the effects of customized 3D printed insole and prefabricated insole on plantar pressure and comfort in patients with symptomatic flatfoot. Medical Science Monitor. 2019; 25:3510-9. [DOI:10.12659/MSM.916975] [PMID]

[31] Redmond AC, Crosbie J, Ouvrier RA. Development and validation of a novel rating system for scoring standing foot posture: The foot posture index. Clinical Biomechanics. 2006 21(1):89-98. [DOI:10.1016/j.clinbiomech.2005.08.002] [PMID]

[32] Mazaheri M, Salavati M, Negahban H, Sohani S, Taghizadeh F, Feizi A, et al. Reliability and validity of the Persian version of Foot and Ankle Ability Measure (FAAM) to measure functional limitations in patients with foot and ankle disorders. Osteoarthritis and Cartilage. 2010; 18(6):755-9. [DOI:10.1016/j.joca.2010.03.006] [PMID]

[33] Blake RL. Inverted functional orthosis. Journal of the American Podiatric Medical Association. 1986; 76(5):275-6. [DOI:10.7547/87507315-76-5-275] [PMID]

[34] Pratt DJ. Functional foot orthoses. The Foot. 1995; 5(3):101-10. [DOI:10.1016/0958-2592(95)90000-4]

[35] Henderson WH, Campbell JW. UC-BL shoe insert: Casting and fabrication. San Francisco: Biomechanics Laboratory, University of California; 1967. https://www.rehab.research. va.gov/jour/69/6/1/215.pdf

[36] Desmyttere G, Hajizadeh M, Bleau J, Begon M. Effect of foot orthosis design on lower limb joint kinematics and kinetics during walking in flexible pes planovalgus: A systematic review and meta-analysis. Clinical Biomechan. 2018; 59:117-29. [DOI:10.1016/j.clinbiomech.2018.09.018] [PMID] 
This Page Intentionally Left Blank 